\title{
Traço rítmico
}

\author{
Magda Liane Famil Garcia \\ Universidade Federal de Minas Gerais
}

Este é um livro singular, elegante, encantador. $O$ primeiro desses qualificativos cabe aqui por muitas razóes, mas prefiro começar pela mais visivel, para dizer que Saber de pedra surpreenderá leitores e críticos por resistir a qualquer tentativa de classificaçà em gêneros literários.

Sérgio Sant'Anna, em prefäcio a Saber de pedra, o litro das estátuas.

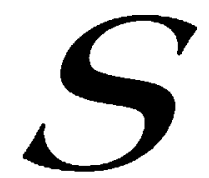

aber de pedra, o liuro das estätuas, com textos de Luis Alberto Brandão Santos e ensaio fotográfico de Ronaldo Guimarães Gouvêa, apresenta as estátuas da ciclacle de Belo Horizonte através da afeção de um toque múltiplo, entre a ficçào e o ensaio, a poesia e a teoria, a imagem e o texto. Afecção é um termo utilizado pelo filósofo Henri Bergson, em Matéria e memória,' e retomado por Deleuze em Cinema I: a imagemmovimento ${ }^{2}$ Le bergsonisme. ${ }^{3}$ Para Bergson há duas categorias de imagens: aquelas que são conhecidas através de uma percepcâo que se situa fora e outras que são conhecidas de dentro, no corpo, através da afeção. A percepção requer um olhar óptico, distanciado, capaz de englobar o espaço a partir de um absoluto, o qual

'BERGSON, 1990.

2 DELEUZE, 1984.

3 DELEUZE, 1999.

- Para estudo sobre o tema: GUIMARÃES, 1997. 
delimita as margens e circunscreve o objeto. Este absoluto englobante define o horizonte ou fundo e faz surgir diferentes planos e a perspectiva a partir da linba concrela, que traçá retas entre o horizontal e o vertical, desenhando figuras geométricas dentro das coordenadas que estriam o espaço liso formado pelo deslocamento do trajeto. A afeç̧ão, assim como a percepção, pode ser constituída por mais sentidos do que o da visão, entretanto, a afeção configura sempre um olhar aproximado, não distanciado do objeto. Portanto, o absoluto do sentido báptico é local, não englobado por um olhar cle fora que se afasta da relação.

Entre o corpo e a pedra, o saber veiculado por Luis Alberto Brandão Santos e Ronaldo Gouvêa faz permear um sentido háptico, criado por um olhar aproximado através da afecção táctil da câmera e da mão do escritor. Diferentemente da imagem formada pela percepção de um olhar projetado de fora, sobre o objeto, o texto e as fotos de Saber de Pedra recebem e transmitem as afecções no corpo da cidade. Estamos sempre dentro do espaço transumante. O percurso faz o intervalo, o trajeto elenca as paradas, o háptico regula a temperatura entre a pele e a pedra, definindo a qualidade e a transcendência das estátuas. Para as estátuas não existe a transcendência do olhar perspectivo sobre o tempo: passado, presente e futuro. Não existe a hierarquização dos fatos, pois toda estátua sabe que sua alma é sua forma variável, que posa e interage apenas nos "muitos presentes: antigos e novos".'

É a partir da relação que se dá entre os organismos, as figuras, os contornos e os pontos das coordenadas que a linha abstrata se desloca. "A linha abstrata é o afecto dos espaços lisos, e não o sentimento de angústia que reclama a estriagem". . No espaço liso "a linha é um vetor, uma direção e não uma climensão ou uma determinação métrica. E um espaço construído graças às operações

'SANTOS, 1999. p. 45.

6 DELEUZE e GUATTARI, 1997. p. 209. 
locais com mudanças de direção"7. É esta linha abstrata, anterior às estruturas dos organismos, que faz o transcurso nômade entre as coordenadas, "tão viva quanto mais é inorgânica", " que vejo compor o corpo da cidade em Saber cle pedra e traçar os nexos narrativos que não se inscrevem unicamente em uma história que é contada a partir de um afastamento englobante. São as "marcas rítmicas anteriores às figuras explicitas" que na linha abstrata carregam a afeç̧ão que conecta pontos c libera o tempo cstriado da cidade de Belo Horizonte e da estíltua nas suas adolescências congeladas. "A linha retilínea e concreta "encontra uma motivação negativa na angústia daquilo que passa, flui ou varia, e erige a constância e a eternidade de um Em-si". "A motivaçào do desejo essencializador aprisiona a cidade na representação figurativa de cartão postal. Por outro lado, diriamos que com a linha concreta se busca traçar o encadeamento retilíneo dos eventos, a fim de estriar os acontecimentos na história inventada para fundar as naçòes modernas. $O$ fluir do "tempo homogêneo c vazio", criticado por Walter Benjamin, ${ }^{12}$ é descrito por um olhar óptico, distante e englobante, que erige monumentos às façanhas de heróismo suicida dos soldados e os sepulta na tumba vazia e coletiva da narrativa histórica ${ }^{13}$ interrompe os tempos paralelos de histórias alternativas, assassinando estudantes que conectam as afeç̧ōes dos sonhos aos gestos conspiradores da linha abstrata e inorgânica das estátuas. ${ }^{\text {H }}$

7 DELLUZE e GUATTARI, 1997. p. 185.

${ }^{*}$ DELEUZE e GUATTARI, 1997. p. 212.

- LeROI-GOURHAN. le geste at la parole, p. 263. Citado em DELEUZE e GUATTARI, 1997. p. 209.

${ }^{10} \mathrm{Cf}$. SANTOS, 1999. p. 20-22.

" DELEUZE e GUATTARI, 1997. p. 209.

12 BENJAMIN, 1987. p. 222-232.

"Cf. SANTOS, 1999. p. 60-62.

"Cf. SANTOS, 1999. p. 90-94. 
Entre Belo Horizonte e a cidade do Cairo observo outra mão se levantar para tocar os desenhos talhados na pedra. A mão quase translúcida de Jorge Luis Borges lê os hieróglifos orientais de um antigo monumento. Desta vez, o olhar cego do escritor projeta uma visão óptica. O sentido engloba o objeto de fora. A imagem de uma percepção exterior à relação pretende a visão nítida do desenrolar linear do tempo e a seleção do passado transforma o talhe da pedra em linguagem, os objetos e acontecimentos em mitos. ${ }^{15} \mathrm{~A}$ linguagem icônica dos hieróglifos petrifica a linha abstrata. Assim, a magia do olhar cego de medusa de Borges transforma a vida inorgânica das estátuas no orgânico estrutural da escrita que documenta, perpetua o passado e estria a memória.

A busca do tempo abstrato, de um "Atlas do tempo" que suspende a relação cambiante dos espaços, é o que percebo nas fotos registradas no livro Allas $^{16}$ e no toque óptico da mão de Jorge Luis Borges sobre os hieróglifos inscritos no monumento da cidade do Cairo, em contraposição com as imagens e o toque háptico de Saber de pedra, que registram a oscilação da temperatura no contato da pedra com a pele e a mutabilidade das redes narrativas da cidade. ${ }^{17}$ Em "Atlas do tempo", " Luis Alberto observa um detalhe apresentado nas margens perfuradas e numeradas dos fotogramas publicados em Allas, de Borges e Maria Kodama: os números das seqüências dos slides, que poderiam tentar revelar o transcorrer natural do tempo, entre as cidades visitadas através da viagem, são sempre os mesmos. Trata-se de uma montagem que simula o tempo e aplaina, com um artificio ordenador, todos os deslocamentos e espaços heterogêneos pela criação de um lugar arquetípico. O lugar, mais temporal que espacial, é a invenção da nação moderna. Luis Alberto focaliza a inscrição chamativa sobre as molduras dos slides: "INDUSTRIA ARGENTINA" e cita as palavras de Borges:

is Cf. SANTOS, 1997. p. 31-37.

16 BORGES, 1984.

${ }^{17} \mathrm{Cf}$. SANTOS. 1999. p. 17.

in Cf. SANTOS. 1997. p. 31-37. 
Meu corpo fisico pode estar em Lucerna, no Colorido ou no Cairo, mas ao despertar a cada manhã, ao retomar o hábito de ser Borges, emerjo invariavelmente de um sonho que ocorre em Buenos Aires". Toda a viagem resume-se à "Buenos Aires pretćrita."

À potência formalizada por uma representaçào figurativa, produzida em um sistema retilineo concreto, ouvimos o contraponto da potência da expressão e não da forma, ${ }^{20}$ en Saber de pedra. A "linha que nada delimita, que já nào cerca contorno algum" "1 quando a estátua da ninfa da Praça da Estação é destruída, elevase na voz, na qual pressentimos a potência acumulada dos sutilíssimos movimentos cinéticos, na intensa velocidade dos átomos do corpo inorgânico das estátuas. ${ }^{22}$ A voz difunde-se e reverbera pela câmara de eco da cidade, "clesencadeando a potência da repetição como uma força maquínica que multiplica seu efeito", "que procede por defasagem, descentramento, ou ao menos por movimento periférico". ${ }^{23}$ A vo\% revela a potência do traço inorgânico, não estrutural, não linear dos nexos narrativos, inscrevendo-se nal imaginação dos transcuntes, nos gestos dos habitantes, nas palavras do escritor. $O$ escritor recolhe, $\mathrm{cm}$ uma levíssima rede de sons, os fios de precisão mineral que ecoam no necessário vàio. As histórias que as estátuas testemunham, entretanto, não constituem o passado que essencializa os acontecimentos no transcurso do tempo. A verdade que as estatuas presenciam é formada pela relação entre os espaços dos presentes novos e velhos. A potência das estatuas encontra-se na vida inorgânica anterior ao desenho figurativo, à mímese e às sombras da cópia lançadas sobre o silêncio c a radiância mincral que refletem toda a imagem no próprio gesto ou olhar que

\footnotetext{
"SANIOOS, 1997. p. 35-6.

" Cf.: DELEUZE e GUATTARI, 1997. p. 210.

" DELEUZE e GUATTARI, 1997. p. 210

2 C. SANIOS, 1999, p.116-9.

${ }^{23}$ DEI.EUZE c GUATTARI, 1997. p. 211.
} 
os toca. As transcendências das estátuas são os nexos criados pelo traço inorgânico das narrativas entre os presentes. $O$ movimento nômade da cidade.

Todavia, entre o passado e o futuro histórico, o traço abstrato libera sons, contados em um tempo rítmico através dos espaços. Ouço o soar mágico de uma estranha música que reata os presentes. O toque háptico do escritor faz audivel a música mineral do Uakti. "Essa música mineral tem o poder de petrificar o Cosmo, ao criar um êxtase de perenidade que subtrai as coisas da ação do tempo"24. O Cosmos da racionalidade histórica é petrificado para que a dança espacial das estátuas seja libertada. O compasso das estátuas gira, fazendo da cidade seu eixo e fluxo. O desenho traçado entre os espaços, no caminho entre um sujeito e o objeto, e a voz musical que reatam as histórias e dão sentido ao caos urbano libera "uma vida germinal inorgânica, uma poderosa vida sem órgãos, um Corpo tanto mais vivo quanto é sem órgãos, tudo que passa entre os organismos"25.

24 SANTOS, 1999. p. 107.

× DELEUZE E GUATTARI, 1997. p. 212. 


\section{Referências Bibliográficas}

BENJAMIN, Walter. Magia e técnica, arte e política: ensaios sobre literatura e história da cultura. 3. ed. Trad. Sérgio Paulo Rouanet. São Paulo: Brasiliense, 1987. (Obras escolhidas, v. 1)

BERGSON, Henri. Matéria e memória. Trad. Paulo Neves da Silva. Rio de Janeiro: Martins Fontes, 1990.

BORGES, Jorge Luis. Allas. Buenos Aires: Editorial Sudamericana, 1984. Colaboraçâo de Maria Kodama.

DELEUZE, Gilles. Cinema l: a imagem-movimento. Trad. Stella Senra. Sào Paulo: Brasiliense, 1985.

DELEUZE, Gilles. Bergsonismo. Trad. Luiz B. L. Orlandi. Sào Paulo: Ed. 34, 1999.

DELEUZE, Gilles, GUATTARI, Félix, O liso e o estriado. In: Mil platôs. Trad. Ana Lúcia de Oliveira. 1997, v. 5, p. 179-214.

GUIMARÃES, Cesar. Imagens da memória, entre o legícel e o intvisíxel. Belo Horizonte: Ed. UFMG/Pós-L.it, 1997.

SANTOS, Luis Alberto Brandalo. Atlas do tempo. In: MACIEL, Maria Ester, MARQUES, Reinaldo (Org.). Borges em dez textos. Belo Horizonte: Sete Letras/ Pós-Lit, 1997.

SANTOS, Luis Alberto Brandăo. Saber de pedra: Belo Horizonte: Autêntica, 1999. 


\section{Resumo}

Este texto propòe uma leitura do livro Saber de pedra, o livro das estâtuas, de Luis Alberto Brandão Santos e Ronaldo Guimaràes Gouvêa, a partir de um diálogo com o irabalho do filósofo Gilles Deleuze sobre a imagem e o movimento. Busca-se focalizar a percepçào dos corpos das estátuas e da cidade captados e transmitidos através do sentido háptico da escrita e do ensaio fotográfico, em contraposiçào ao sentido óptico da linearidacle e da perspectiva histórica.

\section{Abstract}

This text proposes a reading of the book Saber de pedra, o livro das estátuas (Knowledge of Stone, The Book of Statues), by Luis Alberto Brandão Santos and Ronaldo Guimaràes Gouvêa, through a dialogue with the work of the philosopher Gilles Deleuze on image and movement. It focalises on the perception of the bodies of the statues and of the city captured and transmitted through the hiptico sense of writing and photogmphy, in opposition to the optico sense of linearity and of the historic perspective. 